\title{
EL BUEN TRAQUETO VIOLENCIA Y NARCOTRÁFICO EN DOS NOVELAS DEL VALle DEL CAUCA ${ }^{1}$

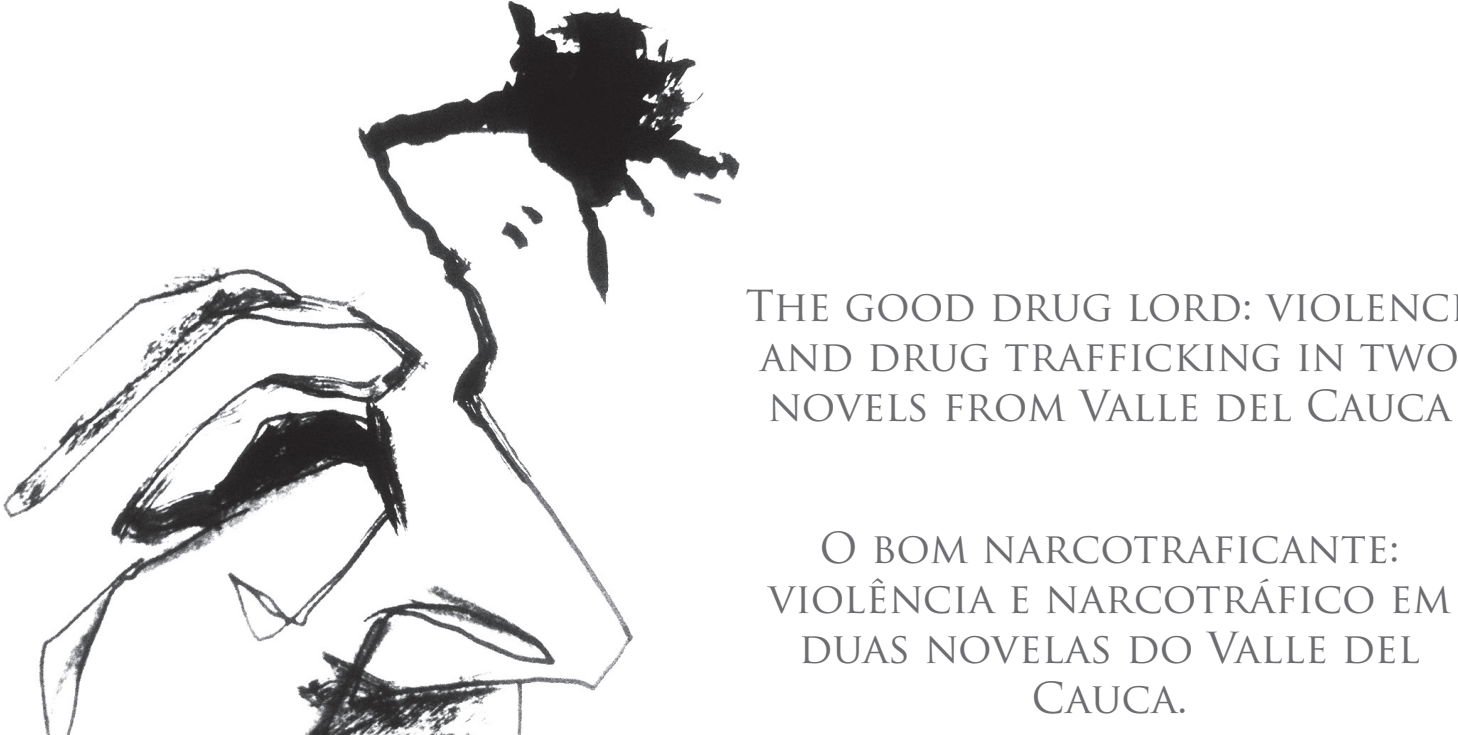 \\ Por \\ Óscar Osorio \\ Profesor Titular \\ Universidad del Valle \\ oscar.osorio@correounivalle.edu.co
}

Resumen: Este trabajo examina la representación de la violencia y el narcotráfico en dos novelas vallecaucanas: Quítate de la vía, Perico, de Umberto Valverde y Comandante Paraíso de Gustavo Álvarez Gardeazábal. Aunque fueron publicadas en los años 2001 y 2002, cuando el país afrontaba un panorama de violencia generalizada que ya no podía entenderse al margen de la economía de la droga, estas novelas desestiman la importancia de la incidencia del narcotráfico en la violencia y ofrecen una mirada sobre el narcotraficante que realza sus atributos positivos y minimiza o desestima su responsabilidad directa en la debacle nacional. Esta visión de mundo pro-narca, desarrollada a través de múltiples mecanismos textuales, permite concluir que esta es una literatura cómplice.

Palabras Clave: Novela y narcotráfico, Novela colombiana, Novela vallecaucana, Literatura y violencia, Literatura y narcotráfico, Literatura vallecaucana, Narconarrativas.

${ }^{1}$ Este trabajo es parte del proyecto de investigación "Novela y violencia en el Valle del Cauca, siglos XX y XXI”, aprobada bajo el código CI-4312, en la Universidad del Valle. 


\begin{abstract}
This work assesses the representation of violence and drug trafficking in two novels from Valle del Cauca: Get out of the way, Perico, (Quítate de la vía, Perico) by Umberto Valverde, and Commander Paradise (Comandante paraíso) by Gustavo Álvarez Gardeazábal. Even though they were published in 2001 and 2002, a time in which the country faced a situation of general violence that could not be understood separated from the illegal drugs economy, these novels disregard the importance of the drug trafficking influence in violence and offer an outlook on the drug lords that highlights their positive attributes and minimize or disregard their direct responsibility in the national debacle. This pro-narco view, developed through diverse textual mechanism, allows us to conclude this is an accomplice literature.
\end{abstract}

Keywords: Novel and Drug Trafficking, Colombian novel, Novel from Valle del Cauca, Literature and Violence, Literature and Drug Trafficking, Literature from Valle del Cauca, Narco-narratives.

Resumo: Este trabalho examina a representação da violência e o narcotráfico em duas novelas do Valle del Cauca: Sai da via, Perico (Quítate de la vía, Perico) de Umberto Valverde e Comandante Paraíso de Gustavo Álvarez Gardeazábal. Embora elas foram publicadas em 2001 e 2002, quando o país arrostava um panorama de violência generalizada que já não podia se entender ao margem da economia da droga, estas novelas desestiman a importância da incidência do narcotráfico na violência e oferecem uma visão sobre o narcotraficante que realça os seus atributos positivos e minimiza ou desestima a sua responsabilidade direta na debacle nacional. Esta visão do mundo pronarco, desenvolvida através de múltiplos mecanismos textuais, permite concluir que esta é uma literatura cúmplice.

Palavras-Chave: Novela e Narcotráfico, Novela Colombiana, Novela do Valle del Cauca, Literatura e Violência, Literatura e Narcotráfico, Literatura do Valle del Cauca, Narco-Narrativas.

Los fenómenos de violencia en Colombia se han dado con mucha intensidad en el Valle del Cauca. ${ }^{1}$ En lo atinente a la violencia de las últimas tres décadas del siglo XX, asociada al narcotráfico, la región estuvo bajo la influencia del Cartel de Cali y, luego, del Cartel del Norte del Valle. Los primeros intentaron un proyecto de inserción silenciosa a la sociedad hegemónica, pero las dinámicas delincuenciales propias de una empresa criminal de tal envergadura, las "limpiezas sociales" y las acciones sicariales y terroristas originadas en su guerra contra el cartel de Medellín trajeron el horror de la violencia y dieron al traste con dicho proyecto. A esto se sumó el accionar del cartel del norte del Valle cuyas vendettas internas, las confrontaciones por mercados, la incontrolada ambición de dominio territorial en la cordillera y la furia homicida de sus protagonistas dejaron miles de muertos y el destierro permanente de campesinos, que terminaban habitando las zonas marginales de las ciudades en condiciones oprobiosas. 
Los escritores vallecaucanos se han acercado a esta realidad desde sus ficciones narrativas y han dejado algunas novelas que indagan el fenómeno e intentan ofrecer una visión más compleja que la de los medios de comunicación y más humana que la de las frías estadísticas. Sin embargo, en algunas de estas ficciones se avala la presencia del narco en nuestra sociedad y se minimiza o se niega el efecto devastador de la economía de la droga en la región. En este ensayo me ocupo de dos novelas que a través de diversos mecanismos textuales sostienen una posición pro-narca: Quítate de la vía, Perico de Umberto Valverde y Comandante Paraíso de Gustavo Álvarez Gardeazábal.

Quítate de la vía, Perico (2001) cubre un período de cuatro décadas, entre los años cincuenta y el año 2001. En la vida del narrador protagonista se destacan tres motivaciones fundamentales: su rumba, sus allegados y sus mujeres. A través de estos tópicos se va dibujando el ambiente nocturno de Santiago de Cali, ese submundo que define al narrador protagonista y que es un componente central de la identidad de esta ciudad durante esas décadas. Se cuenta en detalle la historia de la rumba: auge y declive de las principales discotecas, orquestas, bailarines y cantantes destacados que hicieron presencia en la ciudad. Se registra la historia de la droga en la ciudad y de sus principales capos: Benjamín Herrera Zuleta (el Papa Negro), uno de los pioneros; Jaime Caicedo (el Grillo), el primer capo; los hermanos Gabriel y Samuel González, los capos del Cartel de Cali, ${ }^{2}$ el Cartel del Norte del Valle y otros mafiosos. También se desarrollan múltiples escenas relativas a la experiencia del consumo de drogas por parte del narrador-protagonista y sus amigos, de las mujeres apasionadas por la rumba y de las amantes del protagonista. Con esas historias se configura una cultura popular activa y alegre, pero también desordenada y violenta, que encarna la conciencia social del éxito económico a cualquier precio. El narrador protagonista comparte plenamente esta axiología:

Los principios cambiaron: sólo el más astuto y el más fuerte obtiene la victoria sobre sus semejantes. ¿Acaso, no te gusta el poder? ¿Anhelas riqueza, hermosas casas y mujeres que parecen inalcanzables? Mi padre nos decía que a través de la inteligencia se podía llegar muy lejos. ¿A dónde? A la vuelta de la esquina donde te atracan. La virtud no te lleva a conocer los muslos de Jennifer López. Antes de llegar a la celebridad, otras cien personas han tratado de pasar por encima de ti. Las victorias y las riquezas no llegan solas, antes hay que derramar mucha sangre. El crimen es la ley de esta sociedad. (Valverde, 2001, p. 15).

Ese mundo se construye desde la experiencia del recuerdo del narrador, un hombre que, avanzada su madurez, tiene la sensación de que la buena vida se ha ido, que "todo se derrumbó... Pasamos de la abundancia a la pobreza, se acabaron las fiestas, el auge de las orquestas, la rentabilidad de los leasing" (Valverde, 2001, p. 245). El fin de la fiesta (entiéndase el fin de la rumba intensa, la droga, el sexo, 
el dinero fácil) es lo que produce ese sentimiento de abatimiento en el narrador protagonista, de nostalgia por la época en la cual el Cartel de Cali dominaba el escenario social, cuando los duros se tomaron la ciudad y se podía palpar el agite, el ir y venir de hombres y mujeres afiebrados "buscando la melodía". Esa nostalgia nos ayuda a delimitar con claridad el constructo ideológico sobre el que se edifica la novela: la experiencia vital de este narrador está entroncada en un ideario popular de realización del macho: éxito sexual y económico, es decir, poder. Eso justifica la existencia humana: la vida es la lucha por esos logros, una lucha de hombres duros que son capaces de "ganarle a la vida". Y la manera de ganarle a la vida es llevando droga a los Estados Unidos. Una vez que le ganas, vienes a tu ciudad y te metes a la discoteca de moda con la mujer más bella, y eres feliz. La rumba en la ciudad de Cali es, pues, el escenario en el cual se exhiben los éxitos. La vida del protagonista y sus allegados está orientada de manera plena hacia dicha realización, rápidamente lograda con los dineros del narcotráfico:

"Le ganamos a la vida" resumía el poder de un grupo de personas que habían nacido en barrios populares, de familias de obreros o artesanos (...) El orgullo de haber sobresalido por sus propios méritos, por su audacia y picardía, sin pedir permiso y sin tener confianza en nadie y teniendo la madre como la única persona fiel. "Le ganamos a la vida" era la expresión de una satisfacción plena, que se expresaba en abrazos, sonrisas amplias y besos en las mejillas de los amigos a la manera mafiosa italiana (Valverde, 2001, p. 190).

Aunque se registran episodios de violencia relacionada con los narcotraficantes del norte del Valle y de Medellín, y un par de escenas en las cuales actúan los sicarios Tirofijo, Víctor y Tanga, hay silencio sobre la violencia del cartel de Cali. Como si la época nefanda de la muerte, del desquicie social y la violencia orientada, promovida o ejecutada directamente por el cartel de Cali no hubiese hecho parte de la historia del país. Y, cuando se produce, se origina en la persecución del Bloque de Búsqueda o en los desmanes de otros mafiosos díscolos. Los señores del cartel de Cali son, en la conciencia del narrador, "no más de diez personas que se divertían mamándole gallo a quien lo permitiera" (Valverde, 2001, p. 203). Las investigaciones de Fabio Castillo contradicen esta apreciación. Refiriéndose al mayor de los hermanos Rodríguez Orejuela, anota: “Gilberto Rodríguez Orejuela, nacido en la población tolimense de Mariquita el 31 de enero de 1939, era el hijo de una familia campesina, y tal vez de esa conjunción salió ese hombre ladino que primero da y después exige, a cualquier costo. Su historial delictivo entremezcla el secuestro con el asesinato y la falsificación de moneda con el tráfico de cocaína" (Castillo, 1987, p. 60).

El narrador protagonista está tan complacido con la amistad y la compañía de los capos que parece incapaz de aceptar la responsabilidad de ellos en la debacle social; está tan inmerso en ese submundo de la rumba, las mujeres y la droga que parece no inquietarse por la violencia que lo rodea. Esta desatención es una manifestación de su profunda indiferencia por la violencia y parece resumir una actitud social 
en la que ha ganado la partida una inquietante insensibilidad por la violencia, una experiencia banalizada de la violencia que el narrador se complace en enarbolar permanentemente. Estos son algunos ejemplos: cuando escucha la noticia de la muerte del Ministro Lara Bonilla (uno de los asesinatos que más conmovió al país), el narrador comenta: "Apenas comenzaba la noche y, naturalmente, para nosotros la fiesta continuaba. Me tiré a la pista para abrazar a Roxana” (Valverde, 2001, p. 123). Actitud que se reafirma poco después, cuando Gabriel González (Gilberto Rodríguez) les dice: "Que no se dañe el paseo" (Valverde, 2001, p. 126). Orden que el narrador obedece feliz y se sumerge en el placer inefable de la rumba. En otra ocasión, una bomba es detonada en la discoteca Los Compadres. En medio de la agitación y el desespero de los presentes, el narrador protagonista se levanta, se sacude el polvo y sin reparo por las casi dos docenas de heridos, anota: "Nos miramos a las caras y entendimos que no queríamos acostarnos. Estábamos prendidos y contentos, a pesar del susto. Eran más de las cuatro y media de la madrugada y nos fuimos a Juanchito para seguir festejando..." (Valverde, 2001, p. 194).

10

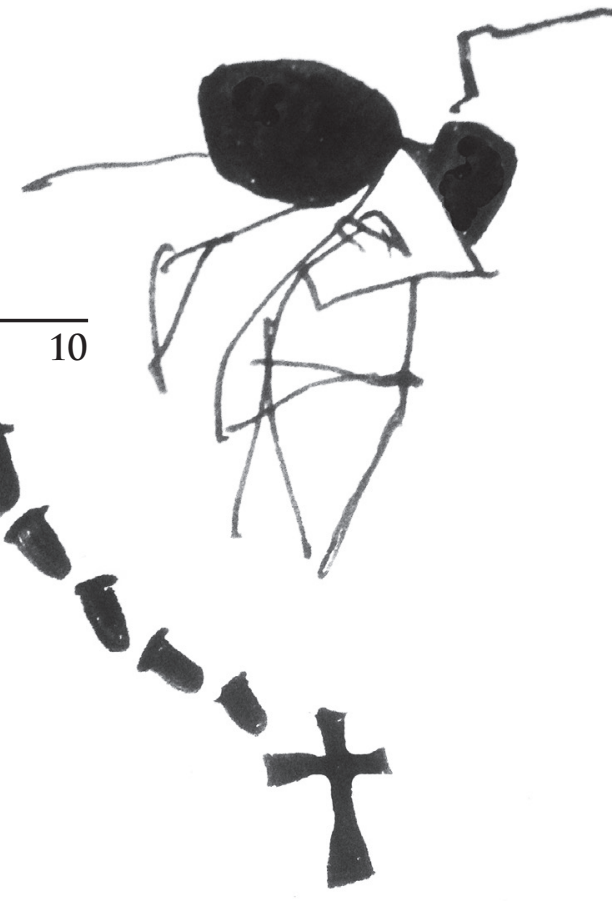

La novela abunda en estas escenas, cuya acumulación deja ya no la mera constancia de esa indiferencia por la violencia sino de una especie de activismo de la indiferencia, que al final de la novela se resume en una frase desafiante del narrador: "Conocí lo que conocí y no me arrepiento de nada. Soy como soy” (Valverde, 2001, p. 255). Este amigo de los jefes del Cartel de Cali y de varios otros narcotraficantes ostenta su tranquilidad de conciencia ante el panorama devastador de una sociedad que se consume en la violencia y el dolor remitiendo a una especie de axiología del cinismo que estaría en la base de su propia identidad como sujeto. Esto da cuenta de su actitud vital y deja una dolorosa constatación del comportamiento de algún sector de la sociedad y de la intelectualidad vallecaucana que contribuyó con ese tipo de complicidad al derrumbe ruidoso y sostenido de la ciudad y del país.

Aunque una de las estrategias reconocidas del cartel de Cali fue la inserción social silenciosa de sus miembros en la sociedad hegemónica, lo que lo distinguió notablemente del cartel de Medellín, esta novela no se interesa en el tema de la inserción social del narcotraficante, pues precisamente todo lo relatado es la constatación de ese fracaso, que el narrador atribuye a la traición de la sociedad hegemónica a los nuevos ricos: "Y los ricos ahí, intocables. Socios de los duros, vendieron fincas, apartamentos, acciones y mujeres. Pero siguen ahí con el dedo acusador, con la doble moral, robándose al Estado, viviendo en Miami o haciendo almuerzos en el club social para levantarse el ánimo, para denigrar de ese cáncer del narcotráfico que le hizo daño a la ciudad" (Valverde, 2001, p. 254-255).

La función irónica de la expresión "ese cáncer del narcotráfico" puesta en boca de los ricos desleales sirve al propósito de descalificar la valoración negativa del fenómeno del narcotráfico. Quienes dicen “cáncer” son los viejos ricos, unos ladrones desleales e hipócritas, socios y amigos de los 
narcotraficantes en las buenas épocas y sus acusadores en las malas. Esa descalificación del enunciador descalifica el enunciado. Hay que tener en cuenta que la valoración negativa del fenómeno del narcotráfico era ya un consenso general en Colombia por los años de publicación de esta novela, lo que implica, insisto, una posición activa del narrador del lado de una valoración más positiva del fenómeno. Esta conciencia narrativa construye un mundo en el que el Cartel de Cali (considerada una de las más poderosas estructuras criminales de Colombia) era un grupo de gente rumbera y mamagallista, sin mayores responsabilidades en la violencia que ha apestado la ciudad y al país durante tantas décadas.

Si bien Quitate de la vía, Perico se ocupa parcialmente del narcotráfico y la violencia en el norte del Valle del Cauca, es en Comandante Paraíso (2002) que se despliegan todas las prácticas de violencia y los entresijos de la economía de la droga en esta región. Esta novela se construye a partir de las voces de distintos sujetos, como resultado de una investigación periodística realizada por alguien a quien todos se refieren como "el doctor", un íntimo amigo del patrón (Gardeazábal, 2002, p. 150) y de otros traquetos que le ofrecen protección total (Gardeazábal, 2002, p. 249). Algunos de los entrevistados se pueden identificar, pero la mayoría no. Entre todas estas voces, tienen mayor importancia la del Comandante Paraíso, que le cuenta al doctor su historia, y una voz de tono académico, que hace la interpretación histórica y etnológica del narcotráfico y la violencia. También aparecen las voces de varios sicarios y una sicaria, mafiosos (uno de ellos a través de cartas que remite a varios personajes, incluyendo a Gustavo Álvarez Gardeazábal, alcalde de Tuluá), delincuentes y vecinos de Alcañiz. La recurrencia de distintas voces en referirse al narratario como “doctor", la aparente transcripción de algunas entrevistas, los varios pasajes en los cuales algunos entrevistados dejan constancia que el periodista está haciendo la investigación con autorización del patrón, la carta dirigida al autor de la novela, entre otras cosas, permiten inferir que la voz dominante es la del narrador investigador, que cuenta la historia averiguada y cita algunos de los testimonios recogidos en su trabajo de campo. Este narrador extra-heterodiegético y la voz académica corresponderían al investigador, al doctor que se llama a sí mismo periodista (Gardeazábal, 2002, p. 207). Las otras voces están subordinadas a él. Toda la historia pasa por el filtro de esta narración subordinante y en ella se configuraría la visión de mundo que orienta la construcción ficcional.

La historia central de la novela es la de Enrique Londoño (Hatoviejo o Comandante Paraíso) y cubre casi toda la segunda mitad del siglo XX. El Comandante es hijo de Anacarsis y del judío Abrahán Izcariote, el padre, asesinado doce horas después de engendrarlo. Anacarsis le busca papá al futuro hijo y se empareja con el carnicero Temístocles Londoño, a quien matan "los últimos esbirros de la violencia" 
(Gardeazábal, 2002, p.26) delante del niño Enrique. Esta doble orfandad, producida por la violencia, marca la vida del hijo. La venganza que el muchacho ejecuta asesinando a los asesinos de su padre, además de indicar la retaliación como uno de los principios rectores de su vida, traza una línea de causalidad directa entre la orfandad violenta y la disposición criminal del sujeto. Londoño es presentado como un hombre muy trabajador, organizado, inteligente, honrado (nunca roba con las cuentas a nadie), generoso, descreído en asuntos de religión, vengativo, violento (un tiro en la frente es la marca reconocida de su estilo), sin compasión, enamorado y feliz, con una vida sexual intensa y sin tabúes:

"Yo he hecho el amor a lo macho-macho, con las mejores hembras, con los mejores muchachos, con unas burras preciosas y hasta con una perra gran danés que me trajeron adiestrada para que no fuera y me mordiera a la hora de la verdad” (Gardeazábal, 2002, p.332).

Son precisamente la violencia y la sexualidad las dos marcas que determinan su identidad y que el mismo Londoño resume muy bien: "Que bota uno más corriente y se tranquiliza más haciendo el amor o masturbándose que matando a alguien. El día que todos nos pusiéramos a culear se acababan las guerras" (Gardeazábal, 2002, p.47).

En los relatos de los narradores subordinados se ofrecen apreciaciones sobre el negocio, la violencia, el oficio del sicariato. A través de estos relatos se completan el perfil del sicario y de narcotraficantes como Gabriel Ángel, que regresará de prisión para seguir en el negocio; y la Arañita, condenado a quince años "por ser colombiano y por venderles a los gringos lo que les gusta” (Gardeazábal, 2002, p.78), después de haber sido extraditado por orden de los mismos a quienes les financió campañas políticas y con quienes se codeaba en los cocteles bogotanos. Se ofrecen detalles del tráfico de drogas y el manejo del dinero, de la corrupción de los agentes y funcionarios del Estado, de los antecedentes y las distintas valoraciones sobre la violencia. Algunas de estas voces son las de los sicarios que cuentan su iniciación: "Hacerlo la primera vez es como todas las primeras veces. A uno le sudan las manos, a otros les da vómito y hay quienes, mientras lo hacen, se les para la pinga con la misma fuerza que los adolescentes masturbantes" (Gardeazábal, 2002, p.13).

Otros cuentan estrategias para incrementar el sueldo, como avisar a la víctima y cobrarle por dejarlo vivo o por denunciar al victimario, avisar a la funeraria para ganar la comisión del 20\% que ellas pagan sobre el valor del funeral. Algunos se explayan en contar sus primeros muertos, su experiencia y sus motivaciones, que en la mayoría de los casos son meramente laborales: “¿-Y uno qué más hace para salir adelante en este pueblo? (...) — Por lo menos los cuchos ya tienen casa nueva, mi hermana estudia en la universidad y yo le puedo gastar a las hembras cuando puedo" (Gardeazábal, 2002, p.9495). Otros reconocen el placer que les causa el asesinato: "Pero a medida que fui cogiendo experiencia, le busqué gusto al asunto y, 
de pronto, hasta entretención al deber y fui clasificando las caras, las muecas y hasta el susto de los caídos" (Gardeazábal, 2002, p.64). De ellos, el más oprobioso es Jaime Serna, el acariciador (torturador), quien "siempre dijo que lo criaron amarrado a un poste" (Gardeazábal, 2002, p.310) y que, afirma su ayudante, "era cruel, pero no por malo sino por gozo” (Gardeazábal, 2002, p. 310). Se señala también la falta de remordimientos: "Uno no se puede arrepentir del oficio. La Virgen del Carmen se lo manda y uno tiene que hacerle para pagar en la vida y no en el purgatorio como ánima bendita. Si no, ¿cómo podría haber levantado a mis muchachos?” (p. 30). Pero la violencia no es privativa de los sicarios, el texto presenta una serie de sujetos degradados, que se benefician del narcotráfico y/o ejercen la violencia sin compunción: “_iY no le da asco ni remordimiento? / _ ¿Por qué? Mi trabajo era recoger los pedazos que ya los habían metido a costales y tirarlos al río” (Gardeazábal, 2002, p.52). Entre ellos, encontramos una magistrada que manda a matar a su esposo porque ya la aburre, a Patty que manda a matar a su novio porque tiene amores con Marcela, a los García de Cajamarca que mandan matar a Julio Fernando porque en un accidente de tránsito en el carro que conducía mueren tres de sus familiares, a los narcos pequeños que siembran el terror en las regiones. Todos los personajes se benefician, de una u otra manera, del narcotráfico y/o la violencia. Incluso, las voces de las víctimas solo aparecen cuando ya se han convertido en victimarios, generalmente al llevar a cabo acciones retaliativas.

Esta polifonía delincuencial nos va dejando algunas ideas sobre el narcotráfico y la violencia en Colombia. La primera, que casi todos los sujetos que transitan por la novela tienen una disposición permanente a la violencia: el asesinato es el método común para resolver dificultades, lograr objetivos, responder ofensas, afianzar el poder, ganarse la vida e, incluso, obtener placer. La segunda, que no hay una sola expresión de culpa, el asesinato está tan normalizado que no se experimenta ninguna conmoción moral quitándoles la vida a las personas. La tercera, que el narcotráfico ha permeado todas las instituciones y el conjunto de la sociedad colombiana con su enorme poder de corrupción, lo que se hace patente en una serie de historias que involucran directamente en el negocio del narcotráfico a ricos y pobres, políticos, militares, policías, curas, monjas. La cuarta, que el narcotráfico es un asunto económico y que, por lo tanto, mientras existan consumidores, y siempre existirán, la única solución será legalizar la droga.

Y si no fuera suficiente con las conclusiones que nos van entregando las historias de vida y las valoraciones que sobre estos temas hacen los delincuentes, el texto nos ofrece una voz académica que hace un análisis de tipo etnológico e histórico sobre el narcotráfico y la violencia, y en cuya explicación sobre las razones de dicha violencia se constata todo lo anterior. Esta voz cuenta la historia del narcotráfico, desde el auge de la marihuana en la Guajira, gracias a la condición nómada y contrabandista de sus gentes, hasta el tráfico de la cocaína y el lavado del dinero. Esta economía, señala esta voz, produce bienestar en la región y logra "lo que no pudo la Revolución Cubana, cambiar de estrato social a los dueños de la tierra" (Gardeazábal, 2002, p.299). Los narcos transforman el campo, lo hacen progresar: "No hay la menor duda, los traquetos le cambiaron la cara al campo colombiano. 
Le metieron la plata que los ricos viejos nunca quisieron poner para que el campo se desarrollara" (Gardeazábal, 2002, pág. 257-258). ${ }^{3}$ La conclusión es: "El problema de la droga es un problema de dinero (...) En ningún momento el problema de la droga es un problema moral para los colombianos. Tampoco para los Estados Unidos. Legalizar la producción de cocaína y marihuana sería una medida universal y conseguirla una actitud de tipo económico" (Gardeazábal, 2002, p.318).

Lo central en el texto es la revisión de las prácticas y dispositivos sociales que hacen posible el enorme desarrollo del narcotráfico y su relación con la violencia. Esto tiene el propósito de sustentar que la causa del desorden social y la violencia en Colombia es el "carácter" del colombiano: una construcción ontológica gestada en el encuentro violento de tres razas violentas durante la Conquista y la Colonia: los indoamericanos, que se masacraban desde hacía siglos; los españoles, que fueron criminales sacados de las cárceles para emprender el viaje al nuevo mundo; los africanos, que eran prisioneros de batallas perdidas y vendidos como esclavos: "Por donde se ve, nuestros orígenes étnicos eran de guerra" (Gardeazábal, 2002, p.111). Se explica cómo esas razas, que venían contaminadas por prácticas de violencia endémica, se mezclan violentamente durante un largo periodo histórico dando como resultado un sujeto necesariamente violento y con una disposición natural al delito. Eso determina que "en este país todos aspiramos a ser pícaros y bandidos alguna vez y es una pendejada que sigamos ocultando ese carácter" (Gardeazábal, 2002, p.73) y explica por qué "en Colombia son muy, pero muy pocos, los muertos por equivocación. Hay más muertos a bala que en accidentes de tránsito y de cada diez cadáveres de homicidios violentos, nueve tienen una explicación en sus comportamientos" (Gardeazábal, 2002, p.71). Esa inclinación delincuencial del colombiano y ese espíritu violento explican la persistencia en Colombia de los innumerables conflictos que constituyen la historia del país: el desorden social, la desinstitucionalización y la violencia son productos de ese "carácter". La violencia, se advierte en la novela, es un problema estructural de la sociedad colombiana, hace parte de nuestra construcción como sujetos sociales, de nuestros orígenes étnicos, de nuestros dispositivos culturales y de nuestra historia. El narrador académico concluye que la violencia "no es más que una célula en descomposición de este proceso inacabable que vive Colombia” (Gardeazábal, 2002, p.284). ${ }^{4}$

En este estado de cosas, el narcotráfico encuentra el nicho ideal para su desarrollo y expansión. Este problema se resuelve con el simple expediente de su legalización o, como pretende el Comandante, cuando los mafiosos se tomen el poder por la vía de las armas y establezcan un gobierno mafioso que logre el reconocimiento de la ONU. De hecho, la novela hace una valoración positiva sobre el narcotráfico. Por ejemplo, plantea que este negocio produjo bienestar económico en los pobres, acceso de los campesinos olvidados a los bienes de consumo y una verdadera revolución agraria que cambió los propietarios de la tierra y desarrolló el campo colombiano modernizando las infraestructuras de producción. 
Dada su condición de judío, el Comandante legaliza sus capitales en New York haciendo negocios con los judíos de esta ciudad. Esta estrategia blinda sus capitales de la persecución estatal y le permite desarrollar una confrontación directa al Estado con una ingente cantidad de recursos económicos que le llegan limpios de USA. En esta novela campea la corrupción, la cooptación, la complicidad social, pero el proyecto de Londoño es mucho más ambicioso. Él busca la instauración de un Estado mafioso, reconocido por la ONU y alimentado por los capitales del tráfico de drogas. Para lograrlo, arma un ejército con el que pretende tomarse el poder. La novela plantea una revolución armada que complete la revolución agraria y consolide lo que el mismo Gardeazábal llamó "la revolución incompleta del narcotráfico".

Precisamente, en "La revolución incompleta del narcotráfico" (1994), un texto publicado en varias versiones, Álvarez Gardeazábal sostiene que las dos condiciones que faltaron al narcotráfico para ser una verdadera revolución fue la de tener un líder que condujera la transformación social y una ideología que la respaldara. El Comandante Paraíso es ese líder y su pensamiento (asesorado por figuras como la de la voz académica o la del "doctor”) comportaría esa ideología. Comandante Paraíso parece expresar la ilusión del autor por completar esa revolución.

Quítate y Comandante fueron publicadas cuando el país había pasado de la violencia al terror, cuando los carteles más antiguos habían sido desmantelados y habían surgido centenares de nuevas y más feroces organizaciones criminales, cuando las principales redes del narcotráfico alimentaban los ejércitos de la guerrilla y el paramilitarismo, cuando la opinión pública conocía las profundas incidencias de la economía de la droga en la violencia colombiana. El mismo año de publicación de Quítate y un año antes de Comandante, Pécaut publicó Guerra contra la sociedad, un libro que recoge ensayos que desde hacía algún tiempo se habían venido publicando en revistas especializadas. Pécaut inicia el capítulo cinco (ensayo publicado en 1997) así:

Desde 1980 Colombia es nuevamente el teatro de una violencia de excepcional intensidad. La tasa nacional de homicidios supera regularmente el 70 por 100.000 habitantes, una de las tasas más altas del mundo. En algunas regiones o ciudades del país, el promedio alcanza 400 por 100.000 . Entre 1980 y 1995 el número de muertos de todo origen superó los 300.000. Las masacres de cinco personas o más son innumerables: solamente entre 1988 y 1993 se cuentan más de 900 de ellas, que provocaron más de 5.000 víctimas. (Pécaut, 2001a, p. 187-188)

Que estas expresiones de violencia no pueden entenderse ya al margen de la economía de la droga es una tesis central en el trabajo de Pécaut: "En realidad, los progresos de la economía de la droga han llegado a alterar todas las separaciones bien delimitadas. Son ellos los que subtienden las interferencias entre protagonistas, ponen a su disposición recursos hasta ese momento desconocidos, provocan efectos sobre el conjunto del funcionamiento de la sociedad y las instituciones; en una palabra, contribuyen a la formación de un nuevo contexto" (Pécaut, 2001a, p. 116). 
Aunque solo una parte de esta violencia se puede derivar directamente de los carteles de la droga, es cada vez más claro para la ciudadanía y para los analistas que la generalización de la violencia y la puesta en jaque de la institucionalidad y la descomposición del tejido social están fuertemente definidas por dicha economía. Sin embargo, en estas dos novelas se hacen valoraciones positivas del fenómeno del narcotráfico y se descarga toda la culpa de la debacle social a los traidores e hipócritas viejos ricos que usufructuaron el negocio y luego contribuyeron a la caída de sus ocasionales socios. En Quitate la violencia producida por el negocio es considerada ya como un mero desmán de algunos bandidos, o producida por los malos del cartel de Medellín o de los descontrolados narcos del norte del Valle, o como reacción normal ante el embate de los ricos traicioneros que "criminalizaron" a los mafiosos mamagayistas. En el caso de Comandante, además de argumento de la traición de los viejos ricos, se explica la violencia como producto de una estructura social disfuncional producida por una condición ontológica del colombiano. ${ }^{5}$

A pesar de la violencia asociada al narcotráfico, en estas dos novelas se valora positivamente este negocio. Se subrayan beneficios para la comunidad, como la abundancia del dinero, el acceso a los bienes de consumo de quienes antes no lo tenían, cierta movilidad social y, en el caso de Comandante Paraíso, una auténtica reforma agraria y desarrollo del campo con los dineros del negocio. En esta novela, además se suscribe (a tono con teorías racistas del siglo XIX) la idea de que el desbarajuste social y la violencia son producidos por una tara racial originada en los procesos de mestizaje del colombiano. ${ }^{6}$ De esa manera se diluyen los efectos perversos e innegables de la economía de la droga en la debacle social colombiana. Y para consolidar esta desviación, el narco aparece dotado de unos valores altamente deseables: valentía, honestidad, sentido de la justicia, generosidad. A través de múltiples mecanismos textuales como los reseñados, estas novelas no solo evidencian la connivencia social con el delito y/o la insensibilidad social con la violencia, sino que ellas mismas están construidas desde esa visión de mundo, desde esta mirada connivente.

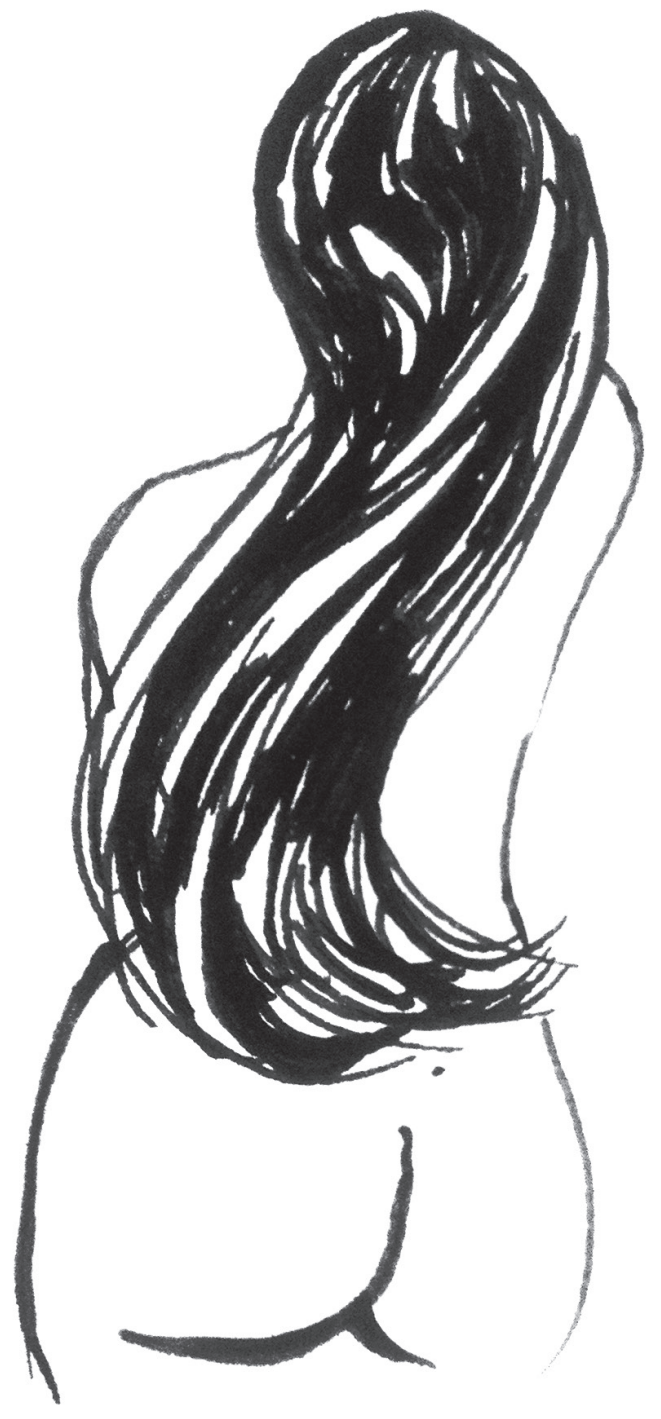


No parece una mera casualidad que en Quítate de la vía, Perico haya una estrategia textual para que el lector identifique al narrador protagonista con el autor de la novela. No aparece el nombre de este narrador, pero podemos identificarlo como una proyección del autor Umberto Valverde, por la correspondencia en las experiencias de vida. Por ejemplo, el narrador dice: "En 1989, el periodista cubano José Pardo Llada me nombró Director Artístico de la Feria de Cali, con el respaldo del Alcalde Carlos Holmes Trujillo" (Valverde, 2001, p. 165). Efectivamente, ese año Pardo Llada nombró Director Artístico de la Feria al escritor Umberto Valverde. Esta clara intención de parte del autor de ser identificado con el narrador de su novela y el evidente carácter autobiográfico de la misma permite afirmar que hay equivalencia entre la valoración de mundo del autor y la del narrador. Paradójicamente, en el paratexto "Aclaración necesaria” se informa que el texto es ficción, que "los nombres propios deben considerarse como pseudónimos" y "cualquier semejanza entre vida y literatura es una mera coincidencia y no hay lugar para especulaciones”. Leyendo la novela y la historia de la ciudad resulta imposible hacer caso de la nota.

Respecto de Comandante, Claudia Ospina (2010)anota:

Son constantes las auto referencias del escritor Gustavo Álvarez Gardeazábal en estas cartas. De las quince cartas que escribe Gabriel Ángel, dos van directamente dirigidas a Gardeazábal y en tres más menciona al escritor cuando ejerce su cargo de alcalde de su ciudad. En la novela, Gabriel Ángel está preso en Estados Unidos en el mismo año en que Gardeazábal inicia su trabajo como alcalde de Tuluá, en 1988. Coincidencialmente, la primera carta de este preso dirigida directamente al escritor está fechada el año en que Gardeazábal es alcalde por segunda vez en Tuluá, en 1992. Se añade el detalle de la dirección en esta carta la cual es la dirección real de correo del escritor en Tuluá (Tittler 215). La segunda carta del preso a Gardeazábal está fechada el día en que el escritor cumple 50 años, el 31 de octubre de 1995 y fecha en la que el preso saldrá libre tras cumplir su condena (Ospina, 2010, p. 214, nota 188).

Además de todos estos anclajes de la ficción en la realidad (bien señalados por Ospina), es fundamental tener en cuenta que Gabriel se refiere a su narratario, Gustavo Álvarez Gardeazábal, como “doctor”, igual que lo hacen otras voces, y que la voz académica de la novela sostiene las mismas ideas que Álvarez Gardeazábal sustenta en algunos ensayos publicados. Esto permite inferir que en el periodista o novelista investigador de la ficción se proyectan algunas ideas del autor. Y ya he argumentado que es precisamente a través de este narrador subordinante que se construye la visión de mundo que modaliza el enunciado ficcional. 
Estas estrategias textuales de afirmación de correspondencia entre los autores y los narradores que promueven una actitud de connivencia con el narcotráfico y silencian o minimizan la responsabilidad directa de los narcos en la violencia y el desbarajuste social, resulta éticamente censurable. Es importante mencionar que Umberto Valverde fue amigo personal de los hermanos Rodríguez y dirigió la Revista del América en la época en que ellos eran los mayores accionistas del club. Por su parte, Álvarez Gardeazábal firma la novela en Alcañiz y en la Escuela de Policía Simón Bolívar 19962002. Esto quiere decir que escribió (o concluyó) la novela durante su estancia en la cárcel, mientras cumplía una condena de seis años y seis meses que le fue impuesta por enriquecimiento ilícito, debido a un negocio con un testaferro del narcotráfico ${ }^{7}$. Pero esto no es nuevo en el Valle del Cauca. Aparte de las biografías de los autores y las relaciones que hayan podido tener con narcotraficantes, es necesario reconocer que la percepción del narcotráfico en el Valle del Cauca fue diferente a la de otras regiones. En gran medida por la estrategia de intervención social del cartel de Cali que se definía por su prudencia frente a la sociedad hegemónica, su bajo perfil político, su inserción económica a través de la industria y el comercio, su discreción y su capacidad de cooptar amplios sectores sociales. También habría que acotar que la compra de medios de comunicación, como la Revista del América y el Grupo Radial Colombiano, fue una estrategia que ayudó a la preservación de ese silencio sobre sus actividades y, especialmente, sobre su violencia.

En 1990, una década antes de la publicación de estas novelas y en pleno esplendor del cartel de Cali, el silencio de la prensa respecto de las actividades de los narcotraficantes caleños y de la violencia producida por el narcotráfico es señalada por Camacho Guizado y Guzmán Barney (1990): "Sorprende eso sí, la conspicua ausencia de personas vinculadas con el narcotráfico, aunque en este terreno particular la información periodística es poco menos que lamentable. Por alguna razón, se oculta casi que sistemáticamente la mortalidad producida por este negocio, excepto la que victimiza a pequeños expendedores callejeros, aunque su letalidad sea de conocimiento público” (Camacho y Guzman, 1990, p. 80). Un año después (1991) insiste en ello Fabio Castillo: "Gilberto Rodríguez Orejuela era el heredero natural de las acciones que diez años antes había iniciado El Grillo, un oscuro hombre que llegó a controlar el mercado de cocaína en Bolivia, y cuyas actividades nunca se mencionaron en los medios de Cali, pese a sus ostentosa evidencia” (Castillo, 1991, p. 57). Lo repite al año siguiente García Bustos: "A diferencia del núcleo antioqueño, el caleño ha estado integrado por sectores de clase media y alta, por lo que su inserción en el tejido social se ha venido realizando sin mayores traumatismos" (García Bustos, 2002, p. 64).

No podemos perder de vista que entre 1987 y 1988 los carteles de Cali y Medellín sostuvieron una guerra que dejó cientos de muertos en todo el país, pero especialmente en estas dos ciudades. Una guerra que incluyó ejércitos de sicarios y atentados terroristas. 
Este panorama de violencia que las novelas desestiman, minimizan, silencian o justifican en causas no asociadas al narcotráfico y la evidencia de los distintos mecanismos textuales a través de los cuales se construye una imagen positiva del narcotraficante permiten concluir que estas novelas vallecaucanas están modelizadas por una construcción ideológica definida por una posición pro narca. Es, en ese sentido, una literatura cómplice.

\section{Notas}

${ }^{1}$ A propósito de la literatura que se ocupa de estos fenómenos de violencia en Colombia, he publicado recientemente los libros La novela del narcotráfico en Colombia y LaVirgen de los sicarios y la novela del sicario en Colombia.

${ }^{2}$ Aunque los demás capos aparecen con sus nombres verdaderos en la novela, a los capos del cartel de Cali se les cambian: Gabriel González es Gilberto Rodrígez Orejuela y Samuel Gonzáles es Miguel Rodríguez Orejuela.

${ }^{3}$ Esta es una tesis muy discutida. Si bien es cierto que algunos narcotraficantes han invertido en la industrialización agrícola, también lo es que en muchos territorios la compra de tierras por narcotraficantes se ha hecho sobre la base del terror y desplazando a poblaciones enteras. Reyes Posada reconoce estas dos condiciones. En un pasaje afirma: "Las orientaciones del modelo económico que guían las inversiones agrícolas de los narcotraficantes comienzan a percibirse en varias regiones del país. (...) Por lo pronto se ha informado del impulso a la dotación de infraestructura física de las haciendas y de la red vial secundaria que las comunica con las carreteras troncales. Algunos narcotraficantes hacen aportes al desarrollo social de las localidades" (Reyes Posada, 1990, p. 130-131); en otro pasaje anota: "En regiones como San José del Guaviare-Calamar la llegada de los traficantes provocó una aguda desorganización social: aumentaron dramáticamente los homicidios relacionados con la droga, se estableció la práctica de pagar salarios en bazuco (crack) y aumentó la drogadicción entre los cultivadores y obreros, creció la prostitución y el consumo suntuario de la población” (Reyes Posada, 1990, p.131). Pero, además, si ocurre que en algunas regiones el narcotráfico eleva algunos indicadores económicos esto no necesariamente debe asociarse con la prosperidad regional. Así lo señala Pécaut: “Algunos trabajos recientes, que parten de observar las coincidencias entre polos de producción de riqueza y violencia, deducen que la violencia está vinculada a la prosperidad, lo que es una afirmación un tanto simplista que no tiene en cuenta las masas desposeídas que afluyen a estas zonas y que no son invitadas al festín” (Pécaut, 2001a, p. 199).

${ }^{4}$ Está muy generalizada la idea de que la violencia en Colombia se reedita en distintos momentos históricos, esto es, que es una misma violencia continua y no distintos fenómenos de violencia: "No hay entonces nada de asombroso en que numerosos colombianos estén persuadidos de que la violencia no puede tener fin, ni en que, hacia 1978, no hayan visto en ello sino el reinicio de la antigua violencia" (Pécaut, 2001a, p.111). El analista francés señala que efectivamente hay unas continuidades reales: de los grupos de autodefensa a las guerrillas, algunas localizaciones de la violencia actual se dan en zonas de la Violencia antigua, similitudes entre los pájaros de los cincuenta y los sicarios de los noventa, algunos de los primeros cuadros de la guerrilla fueron familiares de víctimas de la Violencia de los cincuenta, la reivindicación agraria que persiste en las FARC, la precariedad del Estado y la ausencia de una simbólica nacional. Sin embargo, precisa Pécaut, "este contexto no implica que Colombia haya sido permanentemente el teatro de una violencia efectiva” (Pécaut, 2001a, p.115) y señala períodos de tranquilidad. Concluye Pécaut: "Todo parece distinguir el episodio actual de violencia del anterior. Ciertamente, también conlleva una dimensión política fuerte. En efecto, es la renovación a gran escala del movimiento guerrillero que marca su comienzo y expansión continua la que le confiere siempre una de sus características. Pero a lo largo de los años otras formas de violencia vienen 
a añadirse, cuya dimensión política es ausente o débil, que están ligados a la expansión de la economía de la droga, a la ira de los jóvenes de las periferias urbanas, a la delincuencia común o a las escenas de la vida cotidiana” Pécaut, 2001b, p. 44-45).

${ }^{5}$ Este argumento está bastante desprestigiado en las ciencias sociales. Waldmann (2007), en la nota 3, afirma: "The only alternative would be the anthropological hypothesis that 'the Colombian' has an innate propensity to violence, which I consider to be nonsense" (Waldmann, 2007, p. 607). Sin embargo, el enfoque de Waldman parte de la idea de la existencia de una cultura de la violencia en Colombia. Idea que tampoco resulta bien acogida por algunos investigadores del tema. Respecto a esto, Camacho Guizado y Guzmán Barney afirman: “Al hallar que la violencia urbana en Cali se expresa en determinados ámbitos de la vida social, lo que quiere decir que en algunos no está presente, nos afianzamos tanto en nuestra perspectiva según la cual no estamos completamente convencidos de la pertinencia de adoptar como punto de partida la hipótesis de la existencia de una cultura de la violencia. Hacerlo implica el peligro de considerar a una sociedad como inherentemente violenta” (Camacho y Guzmán, 1990, p. 17). Pécaut también expresa su desacuerdo con esta hipótesis: "Por lo demás, no creo que exista una especie de 'cultura política' colombiana que predisponga a los colombianos a optar por la violencia” (Pécaut, 2001a, p.20).

${ }^{6}$ Idea que, a pesar de su anacronismo, sigue siendo sustentada por novelistas como Franco Ramos en Rosario Tijeras y Fernando Vallejo en LaVirgen de los sicarios. Hago un análisis de estas novelas en mi libro LaVirgen de los sicarios y la novela del sicario en Colombia.

${ }^{7}$ Es muy significativo también que en una reciente entrevista con Darío Henao y Edgard Collazos para el programa Conversan dos del canal regional Telepacífico, emitido el 17 de febrero de 2012 y que se puede ver en http://gardeazabal.co/?page_id=557, Gardeazábal cuenta la siguiente anécdota: "Tenía dos oportunidades: la de convertirme en el Comandante Paraíso y ponerme al mando de un grupo armado en contra del Estado colombiano y, la otra, la que me ofrecieron en San Andrés Simón y Edgar, de que me fuera exiliado. Yo lo pensé mucho, pero jamás he querido irme del terruño" (00:33:56 a 00:34:21).

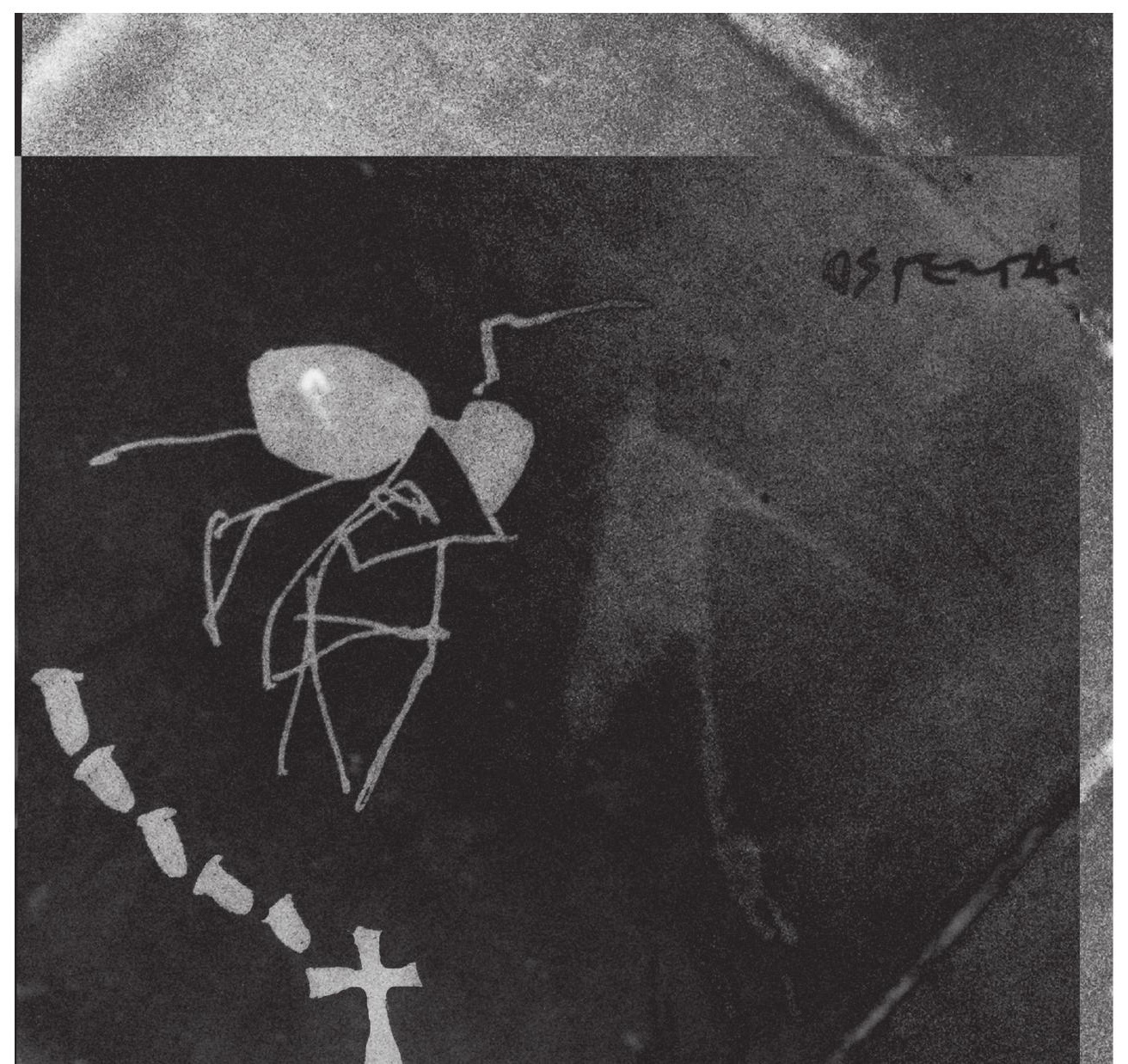




\section{Referencias}

Álvarez Gardeazábal, Gustavo. (1994). "La revolución incompleta del narcotráfico: una revolución sin filosofía."Revista de la Universidad de Caldas 14. 2-3 pp. 99-110. Impreso.

. (2002). Comandante Paraíso. Bogotá: Grijalbo, 2002.

(2010). Entrevista con Darío Henao y Edgard Collazos. Conversan

dos. Cali: Telepacífico. Tomado de: http: / / cvisaacs.univalle.edu.co/index.php/medios-1/ conversan-dos/programas-conversandos/306-conversandos/2433-gustavo-alvarezgardeazabal.

Camacho Guizado, Álvaro y Álvaro Guzmán Barney. (1990). Colombia, ciudad y violencia. Bogotá: Foro Nacional por Colombia.

Castillo, Fabio. (1987). Los Jinetes de la cocaína. Bogotá: Documentos Periodísticos. Impreso. . La coca nostra. (1991). Bogotá: Documentos Periodísticos.

García Bustos, Martha Luz. (1992). "Los focos de la mafia de la cocaína en Colombia." Nueva Sociedad 121. 60-67. Tomado de: http://www.mamacoca.org/docs_de_base/Cifras_cuadro_ mamacoca/Los_focos_de_la_mafia_de_la_cocaina_en_Colombia_\%20Martha_Luz_GarciaBustos_NuevaSociedad121.pdf

Osorio, Óscar. (2013) La Virgen de los sicarios y la novela del sicario en Colombia. Cali: Secretaría de Cultura del Valle del Cauca. (2014). La novela del narcotráfico en Colombia. Cali: Universidad del Valle.

Ospina, Claudia. (2010). "Representación de la violencia en la novela del narcotráfico y el cine colombiano contemporáneo”. Diss. University of Kentucky, 2010. Tomado de: http:// uknowledge.uky.edu/cgi/viewcontent.cgi?article=1042\&context=gradschool_diss.

Palacios, Marco.(1995). Entre la legitimidad y la violencia, Colombia, 1875-1994. Bogotá: Norma.

Pécaut, Daniel. (2001a). Guerra contra la sociedad. Bogotá: Planeta

. "Reflexiones sobre la violencia en Colombia" (2001b). En Violencia, guerra y paz. Una mirada desde las ciencias sociales. Trad. Anthony Sampson. Cali, Colombia: Universidad del Valle.

Reyes Posada, Alejandro. (1990). “La violencia y la expansión territorial del narcotráfico.”Tokatlian, Juan y Bruce M. Bagley (comp.). Economía y política del narcotráfico. Bogotá: Cerec/Uniandes, 1990: 117-139.

Valverde, Umberto. (2001). Quítate de la vía, Perico. Bogotá: Espasa.

Waldmann, Peter. (2007). “Is There a Culture of Violence in Colombia?” Terrorism \& Political Violence 19.4 (2007): 593-609. Tomado de http:/ /www.ijcv.org/index.php/ijcv/article/ viewFile/21/21.

Recibido: 30 de abril / Aprobado: junio 1 de 2015 